\title{
Corrigendum \\ Modulation of Auditory and Visual Processing by Delta-9-Tetrahydrocannabinol and Cannabidiol: an fMRI Study
}

Toby T Winton-Brown, Paul Allen, Sagnik Bhattacharrya, Stefan J Borgwardt, Paolo Fusar-Poli, Jose A Crippa, Marc L Seal, Rocio Martin-Santos, Dominic Ffytche, Antonio W Zuardi, Zerrin Atakan and Philip K McGuire

Neuropsychopharmacology (201 I) 36, 1778; doi:10.1038/npp.20II.58

Correction to: Neuropsychopharmacology (2011) 36, 1340-1348; doi:10.1038/npp.2011.17; published online 16 March 2011
In this article, the third author's name was spelled incorrectly; the correct spelling is Sagnik Bhattacharyya. 